\title{
Providing a scientific and technical basis for repository decisions
}

The Nuclear Waste Policy Act (NWPA) of 1982 directed the U. S. Department of Energy (DOE) to research sites and design a deep geologic repository for the disposal of our nation's spent nuclear fuel and high-level radioactive waste. In 1987, Congress amended the NWPA and directed the DOE to focus only on Yucca Mountain, Nevada, to determine whether it is a suitable site for a repository.

For more than 15 years, the DOE has been studying Yucca Mountain and has accumulated an enormous amount of scientific and technical information about the mountain and the area surrounding it.

The secretary of energy will decide

2000 whether to recommend Yucca Mountain to the president as a suitable site for a repository. This decision will be based on the scientific and technical information resulting from the Department of Energy's studies of Yucca Mountain and on the views and comments submitted by other governmental groups and the public. One required basis for the secretary's decision will be a scientific analysis called a total system performance assessment.

\section{Total system performance assessment defined}

Total system performance means the complete behavior of a geologic repository system at Yucca Mountain in response to the features, processes, and events that may affect it. A geologic repository would involve both natural and man-made (engineered) systems. These systems would interact with each other, acting as barriers to water - the primary means by which radioactive materials might escape from a repository. Aspects of the natural system at Yucca Mountain include the dry climate and the nearly 2,000 feet of rock between the surface of the mountain and the water table. The engineered system includes such elements as very durable waste packages, corrosionresistant drip shields over them, and the solid form of the waste itself. These natural and engineered systems would work together as one overall repository system. How well they would work together is a key question.

To answer this question, the DOE, the Nuclear Regulatory Commission, and the Environmental Protection Agency require what is called a total system performance assessment, or TSPA. Before such an overall assessment can be done, however, scientists must understand the features, events, and processes that could affect the natural and engineered systems of a deep, underground repository.

To do its job effectively, a TSPA must include all relevant features, events, and processes that could significantly affect the repository's performance. Such a total assessment, however, goes much further. A TSPA projects the total combined behaviors of the various features, events, and processes that would be involved. These combined behaviors include such things 
- Features are physical, chemical, and thermal characteristics of the total repository system - and how they work over time. The rock's structure and hardness, and the way they could respond to heat given off by radionuclide decay, are examples of repository features.

- Events are occurrences that have a specific starting time and are usually of short duration - an earthquake, for example.

- Processes are activities that have gradual but continuous interactions with the overall repository system - for instance, water moving through the mountain.

as water moving through the mountain, the lifetime of the waste packages, the release of radionuclides from the engineered barrier system, and their transport through the natural barrier system.

Using specialized computer software, scientists and engineers build detailed mathematical representations or models, of the features, events, and processes that could affect the performance of the repository. They then incorporate the results of each of these individual, detailed models into one overall mathematical model of the repository system. This overall model of the relevant features, events, and processes - both natural and engineered - is called the "total system performance assessment model." The TSPA model allows scientists to project how a repository designed for the conditions of Yucca Mountain is likely to work over thousands of years.

\section{What the TSPAs tell us}

Using these assessments, scientists and engineers can identify which aspects of the repository system require additional study. They can also identify those elements of the repository system that are most important to their understanding of how well the repository is likely to work. Finally, the assessments tell scientists and engineers where they need to improve either their own scientific understanding or the performance of the repository system itself.

The mathematical computer models for the decision on site recommendation will address the following processes:

- What happens to water as it moves through the system. This process includes groundwater flow, water seepage that may occur in the tunnels that will hold the waste packages, and the effects of groundwater movement due to changes in temperature.

- How the waste packages and drip shields will be affected by chemistry, heat, water, and the physical and mechanical environment inside the emplacement tunnels.

- How radioactive material that could be released from the waste packages would move through the nearly one thousand feet of rock beneath the repository level and reach the water table.

- How radioactive material that could be released to the water table would move south to southeast of the repository and eventually reach a well used for a small farming and residential community.

The TSPA will forecast out to 10,000 years. As required by federal regulations, the projections will cover several situations: expected, disruptive events, and human intrusion. In the expected situation, the repository is not significantly disturbed by either human or natural forces and performs according to design. The second situation that must be modeled covers "disruptive events." The probability of a disruptive event such as a volcano disturbing a repository at Yucca Mountain is extremely low; however, should such a disruption occur, there could be significant consequences. So the TSPA will project the probable behavior and effects of these highconsequence, but unlikely, events. Finally, a separate TSPA must assess what would happen if a human drilled completely through a waste package while exploring for water 100 years after the repository is permanently closed.

The performance of a deep underground repository over 10,000 years or more - longer than recorded human history - can never be proven. Scientists can, however, observe and analyze the results of laboratory and field experiments. They can then compare those observed results with the results projected by the computer calculations and, through the TSPA, gain confidence about the repository's likely performance.

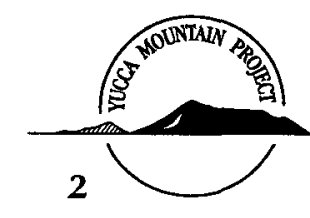




\section{Total System Performance Assessment}

PROCESSES

(e.g., underground water movement, engineered barrier corrosion, radioactive material decay)

\section{EVENTS}

(e.g., climate change, temperature fluctuation, seismic activity)

\section{FEATURES}

(e.g., rock characteristics, engineered barrier components, environmental conditions)
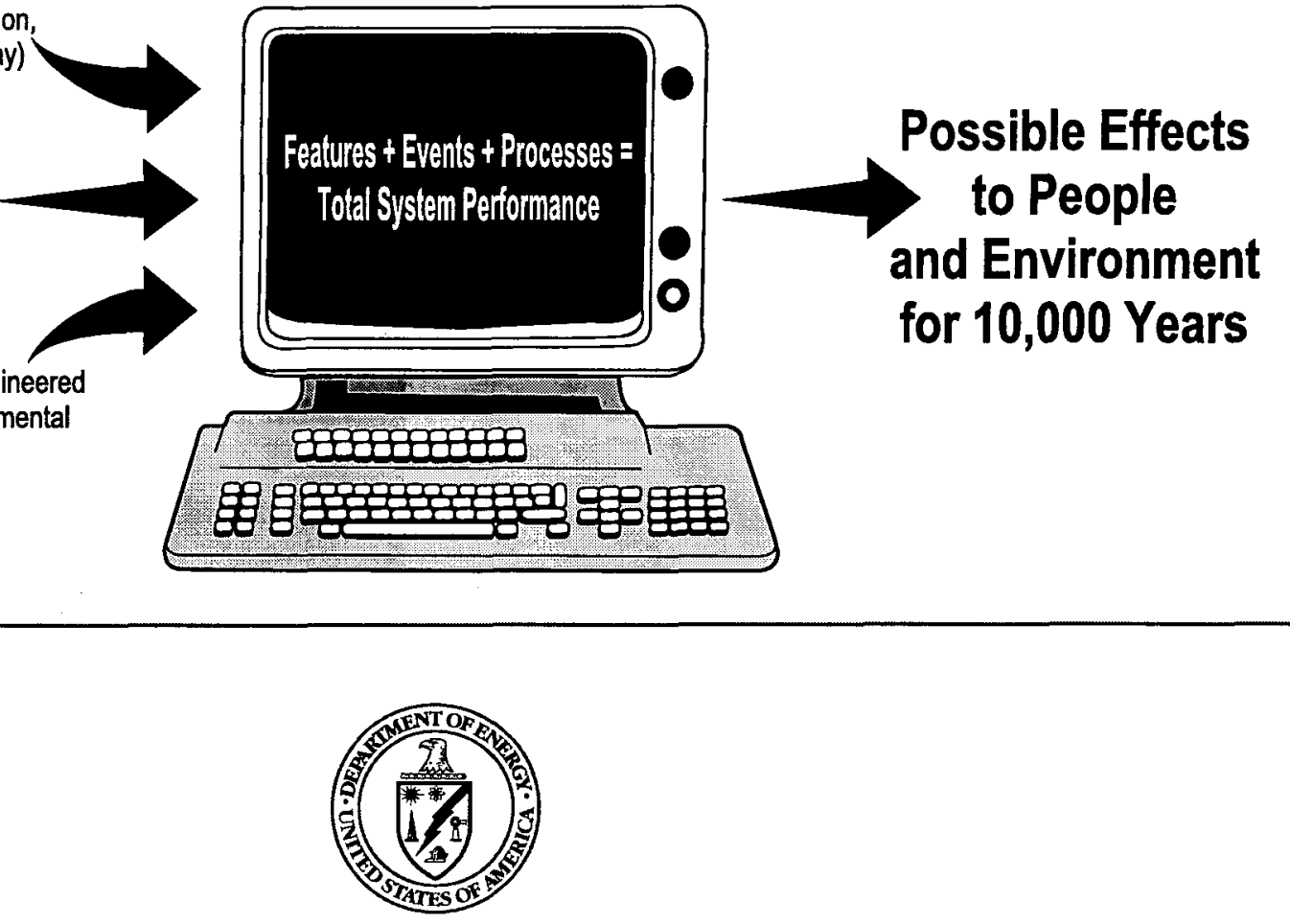

U.S. Department of Energy

Office of Civilian Radioactive Waste Management

YUCCA MOUNTAIN

SITE CHARACTERIZATION
PROJECT

P.O. Box 30307

North Las Vegas, NV 89036-0307

1-800-225-6972

http://www.ymp.gov

DOE/YMP-0202

February 2001

0

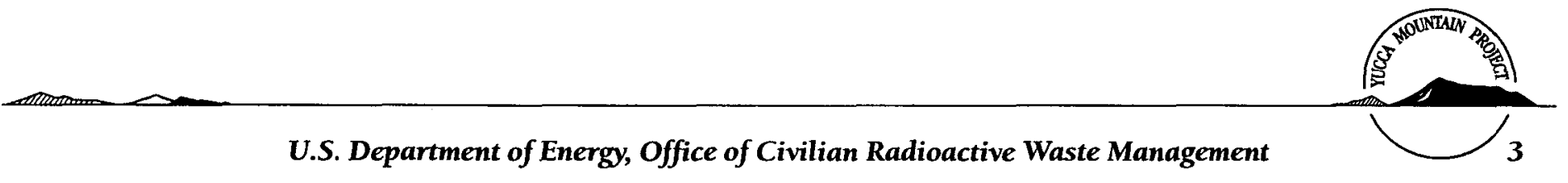

